\title{
Irrigation Fuzzy Controller Reduce Tomato Cracking
}

\author{
Federico Hahn \\ Irrigation Department \\ Universidad Autonoma Chapingo \\ Chapingo, Texcoco, México
}

\begin{abstract}
Sunlight heats the greenhouse air temperature and tomato cracking decreases marketable product up to $90 \%$. A shade screen reduced incoming radiation during warm and sunny conditions to reduce tomato cracking. A fuzzy controller managed greenhouse irrigation to reduce tomato cracking using as variables solar radiation and substrate temperature. The embedded controller presented 9 rules and three assumptions that made it operate better. Signal peaks were removed and control actions could take place ten minutes after irrigation. Irrigation was increased during the peak hours from 12:00 to 15:00 $\mathrm{h}$ when it was required by the fuzzy controller; meanwhile water containing the nutrient solution was removed during very cloudy days with limited photosynthesis. After three continuous cloudy days irrigation should be scheduled to avoid plant nutrient problems. Substrate temperature in volcanic rock can be used as real time irrigation sensor. Tomato cracking decreased to $29 \%$ using the fuzzy controller and canopy temperature never exceeded $30^{\circ} \mathrm{C}$.
\end{abstract}

Keywords-component; Fuzzy controller; irrigation controller; tomato cracking.

\section{INTRODUCTION}

Sunlight intensity control decrease irrigation needs as plants and soil are kept cooler, increasing plant growth as temperature drops off [1]. Cuticle cracking is a physiological disorder that occurs at the beginning of the last phase of fruit growth decreasing skin elasticity [2]. Tomato becomes unmarketable for fresh consumption with losses ranging from $10 \%$ to $95 \%$ of the total fruit. Summer crack unmarketable tomatoes are caused by high air temperature within the greenhouse [3], so shading becomes an alternative, although tomato yield decreases. Retractable roof shade houses are structures covered with polypropylene, polyethylene, or composite fabrics save up to $30 \%$ in energy [4]. Screen systems reduce heat radiation losses at night, and decrease the energy load on the greenhouse crop during sunny conditions. Constant daily light integral achieved only through shading or supplemental lighting [5], induces plant growth passing from its initial transplanting state to its harvest state in 25 days.

Most of the irrigation systems uses ON/OFF controllers, but optimal results are difficult to achieve due to varying time delays and system parameters. A computer-based system controlled irrigation and fertilization in greenhouses; sensors provided feedback information for operating pumps and solenoid valves [6]. Fuzzy theory interprets real uncertainties and becomes ideal for nonlinear, time varying and hysteretic system control. A fuzzy controller system saved water in greenhouses and was cheap to implement [7]. A greenhouse fuzzy climate controller required of 81 rules for proper operation [8]. A simple fertigation fuzzy control presented potential to save water and nutrients [9].

The following paper describes the design, implementation of a fuzzy greenhouse controller which monitored radiation and substrate temperature. Additional nutrients and water were supplied to the greenhouse by an irrigation control to reduce tomato cracking during the hot summer.

\section{MATERIALS AND METHODS}

The 80 x $40 \mathrm{~m}$ University greenhouse at Tlapeaxco, Chapingo was used for the experiment, having natural cooling through lateral and cenital openings. A black Raschel net having a $50 \%$ of transmission was opened manually during the first three months and closed during the summer when tomatoes were produced. Three rows along the greenhouse were transplanted on March 2th, 2009 in volcanic rock substrate (dimensions: $40 \times 40 \times 10 \mathrm{~cm}$ ) with tomato seedlings (Lycopersicon esculentum var. Roma). A solenoid controlled water and nutrient application in each row having tomato plants spaced $30 \mathrm{~cm}$; the irrigation treatments were: A, B and control. Treatment A used the fuzzy controller to apply additional irrigation during hot sunny days and removed water under cloudy conditions. Treatment B added water with the fuzzy controller under whichever weather condition. The last treatment used the conventional controller and did not use any kind of shading. Red tomatoes were harvested on the first of June and one month later cracking was evaluated per treatment.

A fuzzy controller was selected for this application as precise mathematical modeling of the controlled object is not required becoming simpler to implement. Two photometric sensors (model LI-210SB, Li-Cor Environmental Division, USA) measured illumination providing $10 \mathrm{mV} / 100 \mathrm{klux}$ being cosine corrected up to 80 degree angle of solar incidence. The sensors were calibrated against a standard lamp and presented a sensitivity of $20 \mathrm{uA}$ per $100 \mathrm{klux}$ and a response time of 10 microseconds. One sensor was placed in the shading area, and the other in the area without control. Radiation was acquired every thirty seconds averaging ten continuous measurements.

Substrate temperature was measured with one thermocouple fixed horizontally $8 \mathrm{~cm}$ from the pot top and beneath the dripper. The $\mathrm{J}$ cooper constantan type thermocouple was connected to a module (model TxRail 4-20 $\mathrm{mA}$, Novus, Brasil) to provide a 4-20 mA signal finally converted by means of a resistance to voltage. Platinum RTD sensors (model RP502T22, Advanced Thermal Products, USA) measured canopy temperature and was fixed beneath the 
leaves. Six substrate and canopy temperature measurements were acquired every 30 seconds from six plants selected randomly. Temperature and radiation values were stored in a datalogger (model CR1000, Campbell Scientific, USA). Daily stored data were analyzed, comparing treatments behavior and when high differences were noted a revision on the sensor network and irrigation drippers was carried out.

\section{A. Fuzzy membership functions and rules}

Fuzzy evaluation methods process all the variables according to predetermined weights and decrease the fuzziness by using membership functions; therefore sensitivity is quite high compared to other index evaluation techniques. The fuzzy input membership functions determine the variables that are going to be acquired to develop the control. It is desirable to reduce the number of functions in order to minimize the number of rules and the data contained in microcontroller memory. Two input membership functions were used; the first one employed the substrate temperature and the second one the radiation, "Fig. 1". The temperature function presented three groups: COOL, FRESH and WARM temperature, being the latter trapezoidal for values over $20^{\circ} \mathrm{C}$. The second function is composed of three radiation groups named sunny (SUN), cloudy (CLOU) and very cloudy (VC). The very cloudy group of black and rainy sky presents the lowest radiation; a clean sky radiates strongly and forms part of the sunny triangle.

Once the variables are acquired several rules establish the actions that control the greenhouse tomato crop, Table I. The two control actions are to indicate when to irrigate and to increase irrigation and nutrient application. For example a WARM temperature AND sunny radiation will irrigate the crop (IRR) and add an additional $30 \%$ of water and $15 \%$ of nutrients (ADNUT). In the case of a COOL temperature AND very cloudy radiation (VC) the plants will not be irrigated (NON IRR) and zero additional nutrition applied (ZNUT) due to poor water and nutrient uptake. The AND condition was done with the minimum algorithm. A real time clock controlled the fuzzy rules during the 9:00-17:00 hr period. Every one and a half hour starting at $9 \mathrm{AM}$ drip irrigation was applied for seven minutes. A total of seven periods were programmed per day, but the fuzzy controller could apply five minutes more during the irrigation periods of 12:00, 13:30 and 15:00, increasing water application by $30 \%$.
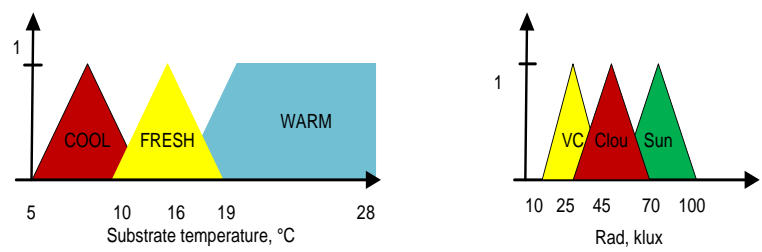

Figure 1. Temperature and radiation membership function

An embedded system used an ATM89C51 micro-controller to control the solenoids to regulate water application per row.
TABLE I. FUZZY RULES TO CONTROL THE IRRIGATION SYSTEM

\begin{tabular}{|l|l|l|l|}
\hline \multirow{2}{*}{ Radiation } & \multicolumn{3}{|c|}{ Nutrient and Water application } \\
\cline { 2 - 4 } & \multicolumn{1}{|c|}{ Cool } & \multicolumn{1}{c|}{ Fresh } & \multicolumn{1}{c|}{ Warm } \\
\hline VC & ZNUT/NON IRR & ZNUT/NON IRR & ZNUT/NON IRR \\
\hline SC & ZNUT/ NON IRR & ADNUT/ IRR & ZNUT/ IRR \\
\hline $\mathrm{S}$ & ZNUT/ IRR & ADNUT/ IRR & ADNUT/ IRR \\
\hline
\end{tabular}

Substrate temperature values between 5 and $28^{\circ} \mathrm{C}$ were converted to a signal varying from 0 to 5 volts. The ADC804 converter acquired the temperature and radiation signals and the digital output was sent to port 1. The real time clock (DS 1706) was connected to port 3 . The fuzzy values were transformed to its membership function using truth tables. Irrigation control turned-on the pump and the solenoids, according to the fuzzy rules used for adding water and nutrients. The same fuzzy rules were carried out by treatments $\mathrm{A}$ and $\mathrm{B}$, but the microcontroller did not remove irrigation on days with limited illumination in treatment $\mathrm{B}$.

\section{RESULTS AND DISCUSSION}

Soil temperature inside the greenhouse nearby the substrate was measured at 9:00, 12:00 and 15:00 h, Table II. At noon the soil temperature covered with the black screen was $5.1^{\circ} \mathrm{C}$ lower than soil exposed directly to the sun. Air temperature measured at a height of $3 \mathrm{~m}$ was $7.2^{\circ} \mathrm{C}$ hotter than the soil temperature. Inside greenhouses, leaves can be cooler than air decreasing transpiration and increasing leaf condensation.

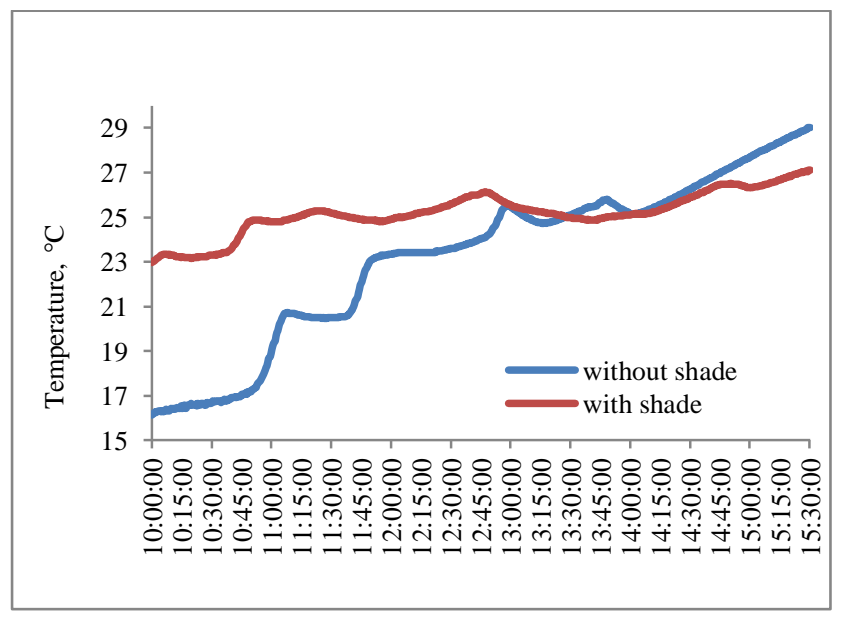

Figure 2. Substrate temperature affected by the shade screen.

Substrate temperature with and without shade becomes alike at 1:00 PM; during the morning shaded substrate temperature is higher, "Fig. 2". Blue line discontinuities result from irrigation. Temperature difference between canopy and substrate was higher when no shading was present and maximum values were encountered in sunny mornings. Many peaks were encountered during unsteady climatic conditions, causing multiple screen movement. Three assumptions were considered for a better controller performance: 
1. At least three peaks were required in the same direction during a period of 15 minutes

2. If one peak occurred in one direction and the next in opposite direction they were cancelled.

3. After irrigation a control action could take place after 10 minutes.

TABLE II. SOIL TEMPERATURE MEASURED AT THREE DIFFERENT HOURS IN A BLACK SHADED GREENHOUSE.

\begin{tabular}{|c|c|c|c|c|}
\hline & \multicolumn{2}{|c|}{ Soil temperature, ${ }^{\circ} \mathbf{C}$} & \multirow{2}{*}{$\begin{array}{c}\text { Light, } \\
\text { klux }\end{array}$} & $\begin{array}{c}\text { Air temp, } \\
{ }^{\circ} \mathbf{C}\end{array}$ \\
\cline { 2 - 3 } & Full sun & $\mathbf{3 0 \%}$ Black shade & 16 & 28 \\
\hline 09:00 a.m. & 17.6 & 19.5 & 70 & 40.3 \\
\hline 12:00 a.m. & 38.2 & 33.1 & 62 & 42 \\
\hline 03:00 p.m. & 42 & 37.7 & \multicolumn{2}{c}{} \\
\hline
\end{tabular}

The three conditions used by the fuzzy controller under operation made it perform better removing instantaneous temperature and radiation peaks. The third rule was the most useful as substrate temperature changes occurred just after irrigation, affecting the substrate temperature signal.

The fuzzy controller was tested when step irrigation was applied; canopy temperature changed after fifteen minutes, "Fig. 3". Substrate temperature decreased by $5^{\circ} \mathrm{C}$ after the twelve minute irrigation session (7 minutes of the normal cycle +5 minutes of the control) in the cloudy afternoon. Although water is applied for twelve minutes, substrate temperature variations will be noted during 20 minutes. Substrate temperature difference between cloudy and sunny days recorded every $5 \mathrm{~min}$ and averaged over each 60-min interval were encountered at the moment of maximum temperature [10]. The fuzzy controller takes ten data and after processing one value will appear every 5 minutes. Substrate daily temperature surpassed soil temperature and when it exceeded $35^{\circ} \mathrm{C}$ for more than 6 hours/day plant injury was expected decreasing internodes spacing [11].

Maximum substrate temperature achieved throughout the month was of $30^{\circ} \mathrm{C}$ and reduced with irrigation as noted in Fig. 3. If root water absorption is less than the rate of transpiration loss, stomata will close, increasing plant and air temperature; transpiration rate reduction in a shaded greenhouse decreased total crop water uptake by $33 \%$ [12].

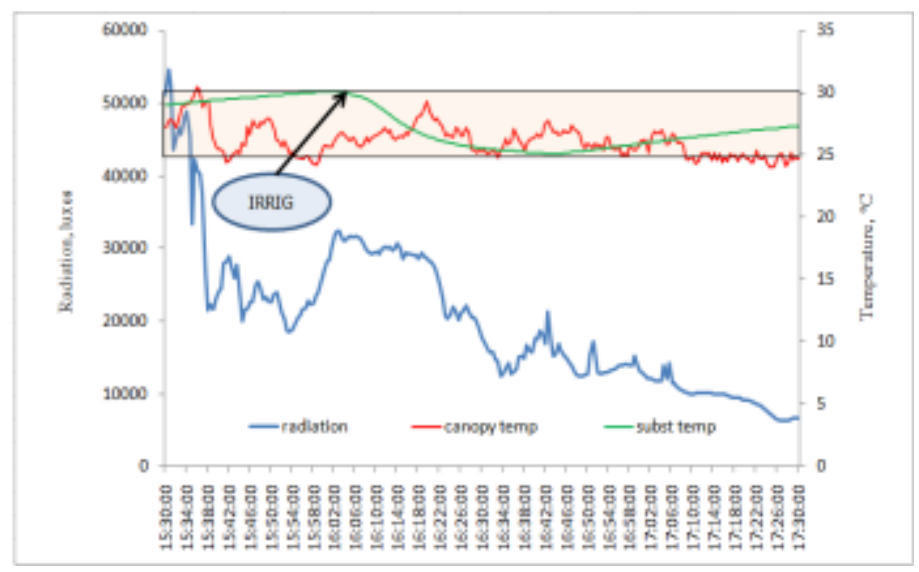

Figure 3. Radiation and temperature differences measured after irrigation.
Substrate temperature was considered a good indicator of canopy temperature during all the day except during irrigation. It can be used as a real time irrigation sensor for volcanic rock substrate characterized by air spaces and low water retention. Thirty hours were not irrigated due to electricity problems, increasing the differential temperature between canopy and substrate to $24^{\circ} \mathrm{C}$ due to very little transpiration; Screens were shot reducing the incoming radiation to the plants. Application of continuous water in dark rainy days increased moisture to $80-90 \%$ so less irrigation was required and nutrients were applied only twice a day. After three continuous cloudy days irrigation should be scheduled for treatment A to avoid plant nutrient problems.

Cuticle cracking appears under high illumination conditions when temperature increases inside the greenhouse. Daily tomato growth variations and tomato heating caused by direct radiation cracked $52 \%$ of the tomatoes as noted on fruits screen-uncovered; rapid tomato daily growth is avoided and can withstand environmental and nutritional variations during tomato growth. Cracking was reduced from $52 \%$ obtained during the harvest of the first of June to $29 \%$ at the harvest of the first of July using the fuzzy controller with treatment A. If water lost by transpiration could not be replenished by the root system, it will use water stored inside the fruit [13]. During night, lower leaf transpiration and root pressure would resupply water to the fruit. Factors such as volume and irrigation frequency affect water uptake by the plants and could be involved in the development of cracking [14]. Canopy temperature never exceeded $30^{\circ} \mathrm{C}$ as additional irrigation was added by the controller. Shading reduced the radiation maintaining fresh the fruits; cracked harvested fruit resulted from tomatoes having cracks at earlier stages.

Fruit weight increased when more irrigation was applied, but in sunny days with high transpiration, water arrival to the fruit decreased. Lack of irrigation once tomato weight exceeds 75 grams, affects its internal pressure and will start cracking the fruits under direct heating. Average weight of the tomato fruits with fuzzy control was $71 \mathrm{~g}$ being $6.4 \mathrm{~g}$ smaller than tomatoes grown without control. Weights of tomatoes grown under fuzzy control were more homogeneous as noted by the standard deviation values of 0.77 and 0.69 for both treatments. In treatment $\mathrm{B}$, the fuzzy controlled supplied additional irrigation and maintained the irrigation cycles during limited illumination. As nutrient uptake by the plants is limited during scarce illumination electrical conductivity increased resulting in $31 \%$ of tomato cracking. The producer noted nutrient and water losses during treatment $\mathrm{B}$ compared with treatment $\mathrm{A}$ presenting both similar tomato average size. Plants without shade presented losses of $52 \%$ by cracking, and although their size was bigger and the yield higher. Different doses of irrigation were applied when half of the days were sunny and half cloudy being screen shading essential to reduce fruit cracking.

Future work includes a movable controlled shade screen as it was opened manually during this experiment; the screen should be opened or closed automatically with a gear motor driven by a photovoltaic system [15]. A pH and electrical conductivity (EC) fuzzy system is required to control 
fertigation more precisely, helping to observe cracking caused by EC variations [9].

\section{CONCLUSION}

This work concludes that tomato cracking can be reduced by setting a screen; Cracking tomatoes harvested during July were reduced from $52 \%$ to $29 \%$. Raschel shading screens reduced incoming radiation, fruit size and yield, but increased marketable production and producer profit. The use of the fuzzy controller regulated canopy temperature which never exceeded $30^{\circ} \mathrm{C}$. Irrigation applied on sunny days helped to maintain a constant fruit growth as well as a better canopy temperature. Less water and fertilizers were used in treatment A than in treatment B where irrigation was still applied under scarce photosynthesis. Substrate temperature measurement could be a new method for scanning real time irrigation in volcanic rock substrates. The fuzzy controller becomes an excellent option for plant growth management and healthy tomato production but shade control should be included.

\section{REFERENCES}

[1] J. Tanny, S. Cohen, and A. Grava, "Airflow and turbulence in a banana screenhouse," Acta Horticulturae, vol. 719, pp. 623-630, 2006.

[2] J. C. Bakker, "Russeting (cuticle cracking) in glasshouse tomatoes in relation to fruit growth," J. Hort. Sci, vol. 63, pp. 459-463, 1988.

[3] T. Wada, H. Ikeda, K. Matsushita, A. Kambara, H. Hirai, and K. Abe, "Effects of shading in summer on yield and quality of tomatoes grown on a single-truss system," Journal Japan Society Horticultural Science, vol. 75, pp. 51-58, 2006.

[4] H.F. Plaisier, and L. Svensson, "Use of adapted energy screens in tomato production with higher water vapour transmission," Acta Horticulturae, vol. 691, pp. 583-588, 2005.

[5] L.D. Albright, A.J. Both, and A. Chiu, "Controlling greenhouse light to a consistent daily integral," Transanctions of the ASAE, vol. 43, pp. 421431, 2000.

[6] K. Kell, M. Beck, and F.W. Frenz, "Automated ecological fertilization and irrigation of soil grown crops in greenhouses with a computer controlled system (KLIWADU),” Acta Hortic., vol. 481, pp. 609-616, 1999.

[7] P. Javadi, A. Tabatabaee, M. Omid, R. Alimardani, and L. Naderloo, "Intelligent Control Based Fuzzy Logic for Automation of Greenhouse Irrigation System and Evaluation in Relation to Conventional Systems", Journal World Applied Sciences, vol. 6, pp. 16-23, 2009.

[8] F. Lafont, and J.-F Balmat, "Optimized fuzzy control of a greenhouse," Fuzzy Sets and Systems vol. 128, pp. 47-59, 2002.

[9] D. Gómez, A. López, G. Herrera, C. Fuentes, E. Rico, C. Olvera, D. Alaniz, T. Mercado, and S. Verlinde, "Fuzzy irrigation greenhouse control system based on a field programmable gate array," Afr. J. Agric. Res., Vol. 6, pp. 2544-2557, 2011.

[10] S. L.Warren, and T.E. Bilderback, "Timing of low pressure irrigation affects plant growth and water utilization efficiency," Journal Environmental Horticulture, vol. 20, pp. 184-188, 2002.

[11] F. Giuffrida, "Temperature of substrates in relation to through characteristics," Acta Horticulturae, vol. 559, pp. 647-654, 2001.

[12] P. Lorenzo, M.L. García, M.C. Sánchez-Guerrero, E. Medrano, I. Caparrós, and M. Giménez, "Influence of Mobile Shading on Yield, Crop Transpiration and Water Use Efficiency," Acta Horticulturae, vol. 719, pp. 471-478, 2006.

[13] F. Jobin-Lawler, K. Simard, A. Gosselin, and A.P. Papadopoulos, "The influence of solar radiation and Boron-Calcium fruit application on cuticle cracking of a winter tomato crop grown under supplemental lighting," Acta Horticulturae, vol. 580, pp. 235-239, 2002.

[14] M. Dorais, A.P. Papadopoulos, and A. Gosselin, "Influence of electrical conductivity management on greenhouse tomato fruit yield and fruit quality," Agronomie, vol. 21, pp. 367-383, 2001.

[15] F. Hahn, "Fuzzy controller decreases tomato cracking in greenhouses," Comput. Electron. Agric., vol. 77, pp. 21-27, 2011.

\section{AUTHORS PROFILE}

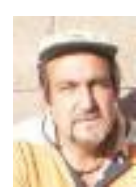
Dr. Federico Hahn

Professor and researcher of biosystems and irrigation technology at the Universidad de Chapingo, Mexico.

Dr. Hahn develops control equipment for farmers and producers. His embedded systems are working around Mexico and other countries. His main areas of expertise are sensors, instrumentation and automation. 